\title{
A methodology proposal for developing Adaptive cMOOC
}

\author{
Ángel Fidalgo Blanco \\ Technical University of Madrid, Spain \\ afidalgo@dmami.upm.es \\ Francisco J. García-Peñalvo \\ GRIAL Research Group, \\ Educational Research Institute, University of Salamanca \\ fgarcia@usal.es \\ Marisa Sein-Echaluce \\ University of Zaragoza, Spain \\ mlsein@unizar.es
}

\begin{abstract}
Massive Open Online Courses or MOOCs, both in their major approaches xMOOC and cMOOC, are attracting a very interesting debate about their influence in the higher education future. MOOC have both great defenders and detractors. As an emerging trend, MOOCs have a hype repercussion in technological and pedagogical areas, but they should demonstrate their real value in specific implementation and within institutional strategies. Independently, MOOCs have different issues such as high dropout rates and low number of cooperative activities among participants. This paper presents an adaptive proposal to be applied in MOOC definition and development, with a special attention to cMOOC, that may be useful to tackle the mentioned MOOC problems.
\end{abstract}

\section{Categories and Subject Descriptors}

D.1.2 [User/Machine Systems], H.3.5 [Online Information Services], H5.2 [User Interfaces], H.5.4 [Hypertext/Hypermedia], K.3.1 [Computer Uses in Education]

\section{General Terms}

Design, Human Factors.

\section{Keywords}

MOOC; Adaptive Systems; Human-Computer Interaction; Moodle.

\section{INTRODUCTION}

MOOCs (Massive Open Online Course) are the courses with the most massive and heterogeneous participation that anyone can find nowadays. In a specific course instance, due to its own open nature, different kinds of students are involved: pre-university students, university students, postdoc students, non-university students, working place students, etc. Also, the students' learning goals are different; some may be interested in knowing the subject, others in applying the knowledge, others in improving what they already know, and even experts in the field enroll in the course to contrast their experience or just to know what others are doing. Thus we can say that different participant with different roles, with different learning goals and with heterogeneous application contexts may coincide in the same MOOC instance.

The first editions of MOOCs suffer from several problems [5], we would like to emphasize three of these weaknesses: 1) a very high dropout rate (around 90\%); 2) low number of cooperative activities (outside peer assessment) among participants; and 3) Poor continuity of learning communities once the MOOC ends.

These and others issues are causing that several educators, researchers and institutions doubt about the effectiveness of the MOOCs, and even take it for granted the failure of these [30].

This research proposal establishes the hypothesis that one of the aspects that may cause the high dropout rate, the lack of cooperative activity between course participants and the non-continuity of learning communities once the course is over is the heterogeneity, the different profiles, the different learning objectives and interests of the participants in a MOOC. If the course has a rigid learning design (the same educational level or methodology for all the students) this can cause participant giving up, even before the course starts, due to all the participants have to follow the same work plan (match their interests or not). The same goes for learning networks and connectivist activities; an activity may be interesting for a group but lack of interest to others.

A MOOC is not another online course but it has different characteristics; the key concept is not to repeat the same classic academic teaching but be able to engage participants to create and share knowledge in a connectionist approach. Thus, applying the adaptive education general concepts for resources access is not enough (this approach is presented by different tutoring and e-learning systems), but they must be completed with knowledge management, informal and social learning and lifelong learning principles. 
The main pedagogical principle behind a MOOC proposal should be that participants be able to create new knowledge in a social and collaborative way, allowing that knowledge may be openly used both to improve the MOOC itself and to give continuity to the MOOC learning community. If this were true (i.e., the MOOC expectations are met) would generate thousands of knowledge resources in different places and by different people, promoting open knowledge and open innovation principles[11]. Therefore, in addition to adapting the learning processes, the learning resources must be managed too, identifying and organizing them by the way they may be used within the MOOC and the knowledge creation activity remains alive after course completion.

That is, the characteristics that make a MOOC difficult to manage (as the mass, heterogeneity, conducting collaborative activities and management of distributed and generated knowledge resources) are, in our research, strengths and identifiers of a MOOC. We call this idea MOOC with connectivist and continuist adaptivity.

These are the keys to achieve a connectivist and continuist adaptivity of a learning design:

- Using adaptive technology and methodology to allow proposing activities that are shared by all the participants, or shared by groups with similar profiles, or individual ones.

- Analyzing the generated data during the learning process (learning analytics) in order to help students to select the most suitable resources for their own goals (adaptive methodology), the collaborative connectivist activities and the relationships with resources more typical for other different profiles.

- Promoting and managing the creation of collaborative resources through learning communities linked to the MOOCs. Participants both individually (for example using blogs) or collaboratively (for example using social networks or wikis) may create useful resources that increase and improve the MOOC learning resource database. The most important challenge is to classify, organize and integrate the dynamically generated within the MOOC in order to reinforce the resource adaptation for the different profiles and also, in the other hand, guarantee the continuity of the connectivist activities once the course is over.

Thus, the proposed research about MOOC are based on:

- Adaptive MOOCs design, taking into account each student's profile, goals and social context.

- Learning data analysis aiming both analyzing the learning outcomes effectiveness and helping students to identify the most suitable resources for their own goals.

- Management of the dynamically generated resources inside the learning communities just in order to integrate them in the MOOC and also in the linked community itself once the course edition is over.

The rest of the paper is organized as follow: Section 2 is devoted to review the most significant works related to the adaptive characteristic of the proposed MOOCs; Section 3 contextualizes the research proposal; Section 4 describes the MOOC design methodology; and, finally, Section 5 closes the paper with some reflections and conclusions, including a presentation of the next steps in this researching approach.

\section{RELATED WORKS}

There is much literature about MOOCs [25; 28], specially blog entries more than academic papers, that have arisen since MOOC inception in 2008 with the massive open online course format pioneered by Siemens and Stephen Downes (Connectivism and Connected Knowledge 2008 -CCK08- course [7]) and there are even studies about this literature [18]. Now, several MOOCs have been developed and there are papers that are centered on to question the MOOC effectiveness of learning [30].

From its own name, MOOCs are massive and open courses whose participants have heterogeneous profiles, thus valuing them these characteristics may be considered both in a positive way, due to the high level learning expansion possibilities [17], and in a negative perspective, when the quality of the process and the assessment is questioned [20] or the low rate of completion of the MOOCs (about 10\% on average) is emphasized [14].

It has also been written about the different types of MOOCs: xMOOCs (certification based courses that follow a more behaviorist approach) and cMOOCs (connectivism and networking based courses) [5;19;29]. They are so distinct in pedagogy that it is confusing to designate them by the same term [13]. This research proposal is more related to cMOOCS due to they apply the connectivism principles [24] and their social repercussions and learning enrichment.

In this sense, some participants say that only finished those with group activities or periodic face-to-face meetings [20]. As [15] say "In addition, organising small learning groups in the context of a MOOC is a good strategy. The mass collaboration that MOOCs are build on is important, but it is different from the cognitive and motivational support we get from communicating with a small group of people we trust and whose interests we share".

Overcrowding and participants heterogeneity increase the failure in MOOCs, mainly when there exists only one learning model and all the students share the same case studies and activities [23]. In particular, success in a MOOC requires that the student has already learned how to learn, something that for many students is the principle outcome of a college education [6].

According to this, adaptivity is a core characteristic that MOOCs should include in order to achieve successful results, introducing what Nishikant Sonwalkar calls the aMOOC (Adaptive MOOC) concept: "The courses are one-size-fits-all and depend heavily on the video lectures and discussion boards. A MOOC course that adapts to the learning preferences of individual learner using brain-based adaptive learning with learning strategies - apprentice, incidental, inductive, deductive and discovery can lead to much higher completion. The adaptive MOOCs, where the content is presented with differentiated learning strategies and real time intelligent feedback can significantly 
improve completion rates" [26; 27]. Scott Rapp [22] also goes in the same direction with the "Fuse MOOCs with adaptive learning platforms" strategy by iteratively adjusting questions to student's level, the platform intelligently adapts to meet student's needs and help her learn faster and more effectively in the language area.

Adaptivity in learning models improves the learning process, from initial conditions, such as learning style, knowledge level a student's profile, and during the learning process [16]. Learning and cognitive styles have been taken into account as core elements to define adaptive learning methodologies [21]. Adaptive instructional designs based on IMD LD [3; 4] have been proposed using HyCo authoring tool [12]. Adaptive assessment proposals throughout adaptive tests also have been carried out [2].

Recently, the proposed methodology concepts have been applied in the scope of the Spanish Ministry of Industry, Commerce and Tourism Teaching Innova project [9] and will be applied in the workplace training and competences recognition in the scope of the European Union TRAILER project [10].

\section{RESEARCH CONTEXT}

The proposal about using an adaptive learning approach was born with the experience of developing a MOOC entitled "Software Libre $y$ Conocimiento en Abierto" (Open Software and Open Knowledge) [8] in Miríada X platform (https://www.miriadax.net/ in which one 18 Ibero-American universities have been involved, with 48 MOOCs available and 250,000 students enrolled). After an analysis of the firsts editions of the offered MOOCs, ours has the first position ranked by completion rates by involved universities [1].

Some specific data about this edition of our MOOC are: $27 \%$ of completion rate over the total students enrolled in the course $(3,900$ persons), $40 \%$ of completion rate over the total students that started the course.

For this edition a first attempt of adaptive methodology was used (with a manual approach, which was a great effort for the teaching staff) both for resources and activities. To do that, a survey was made at the beginning of each module in order to know the each participant's goals; taking the surveys results into account 4 participant profiles were defined: developers, students with interest in using open software in their studies, persons wishing to apply open software in their respective institutions, and finally those that only wanted to know the open software/knowledge state-of-the-art. Each person participated in the activities proposed on her profile, besides a collaborative wiki was made to share the generated resources.

Miríada $\mathrm{X}$ is a platform for xMOOCs, however our goal was to work with a cMOOC based approach. For this reason, several learning communities were created in different transversal social networks (Linkedin, Elgg, Identi.ca and Twitter, but the most populated and active one was Linkedin) in which ones the social and connectivist activities were developed (outside of the hosting platform). This kind of activities was optional, however more than $75 \%$ of the involved users participated in them, generating resources for the MOOC and the learning community that is still active.

The analysis of the course results allows us to affirm that an adaptive methodology applied in MOOC may be useful to reduce the dropout rate. However, for the collaborative activities a specialized development and a learning analytics study must be carried on to demonstrate the data validity and to define exportable workflows that may be used by any MOOC.

In order to do that, and taking account the previous experience, a new MOOC is proposed about the topic of "Educational innovation", area in which the research team has a wide expertise. Authors have social sites (in Spanish) about this topic with more than 2000 daily visits (http://innovacioneducativa.wordpress.com). More than 400 innovation projects at the University of Zaragoza by members of this work team. Also, there exists an International PhD Programme on Education in Knowledge Society (http://www.usal.es/webusal/node/30026) with researching lines related to this topic. And finally the three participant universities organize the Congreso Internacional sobre Aprendizaje, Innovación y Competitividad (CINAIC 2013, http://cinaic.com).

\section{MOOC DESIGN METHODOLOGY}

The design for the proposed adaptive MOOC is based on non-sequential modules, but on the different MOOC thematic sections each module is applied. The modules act in spiral along the development of the course. There are three kinds of actions that are developed in parallel: 1) data acquisition and assessment; 2) collaborative activities; and 3) resource management.

We use the growth of a tree simile to explain the adaptive MOOC development. The collaborative activities are the development of the tree. Data acquisition and assessment guarantee that the tree grows in the right way. The resource management means the management of the tree fruits; these fruits may be used along the course but also as motivation and engagement for the learning community continuity far away the course ending.

\subsection{Data acquisition and assessment}

In each module, in a parallel way, data acquisition is made both for accreditation purposes and for research ones. The data acquisition is made through assessment (diagnostic, formative and summative- continuous) and the outcomes of the activities made (learning analytics).

The diagnostic assessment is made in order to obtain the profiles, previous knowledge, learning goals, context, etc. From this initial assessment the profiles for grouping activities are generated and also the training activities in the learning community.

The formative assessment is done through the activity-tracking processes. Most of this evaluation will be conducted by the adaptive system used in the MOOC, and that will check the development of activities and their outcomes, and the modification of the training plan.

The summative assessment is done in a continuous way. The final activities outcomes are taken into account. This assessment will be made in three ways: 1) automatically by the system that checks the activity finalization; 2) by peers with emphasis in the quality and the usefulness of the results; and 3) by the teaching staff with researching objectives. 


\subsection{Collaborative activities}

These allow the tree development. The tree grows along the course edition and its fruits are the generated knowledge among the participants. The fruits appear since the early beginning of the course. These fruits are virtual and consequently they may be used along and after the finalization of the course edition. They are of the following types: common activities, group activities and collaborative common activities.

Common activities. Each time that a common activity is done (independently when is done) the tree roots and trunk strength are consolidating. These activities are oriented to know the conceptual foundations and different visions and resources that are related to each profile. They are developed at the MOOC beginning, along the course (collaborative activities for sharing the generated resources in the different profiles) and at the end of the course (organizing the generated resources). Diagnostic assessment belongs to this kind of activities.

Group activities. Following the tree simile, they are the tree branches. Each branch represents a different user profile. The adaptive system, using diagnostic assessment, proposes personalized activities for each profile, this way the participants' affinity (context and similar learning goals) contributes to the realization of these collaborative activities. The MOOC design wants to take advantage of the participants' heterogeneity, establishing connectivist activities among the different profiles that may be put in common the different students' perspectives about the course thematic, the educational innovation in this proposal.

The group activities are focused on reducing the MOOC dropout rate and establishing closer connectivist links. They are based on the following principles: 1) affinity to define working groups where sharing resources and opinions; 2) resource selection according to the participants' learning goals; and 3) establishing a training plan according to the participants' learning goals.

The group activities outcomes are the fruits that are generated in each branch of the tree. As the course develops, the fruits will become larger and more numerous.

Collaborative common activities. Following the tree simile, these ones mean seeing the tree in whole way. One of the adaptability hazards is that each person sees only the fruits that generate her branch. To avoid it, the collaborative common activities have the goal to classify the different generated resources, organize them (knowing the different tree branches). All in all, they mean that all participants identify and know the different generated knowledge resources, the different profiles and establishing relationships among them. This is a very important issue to allow the continuity of the learning community.

\subsection{Resource management}

It means managing the harvest; taking care about the fruits from the moment they arise so that they can gain weight and build new fruits. If the thousands of MOOC students participate in the collaborative activities and each activity generates knowledge the result will be thousands of resources related to the MOOC theme that gather different point of views about it. Therefore, it is necessary to manage these resources identifying and classifying all the generated knowledge in a continuous process. MOOC participants should do these tasks. Besides, the adaptive system includes resources along the course organizing them according the specific goals and interests of both module and participant.

\section{4 cMOOC adaptivity and resource management outline}

Figure 1 shows the cMOOC adaptivity and resource management scheme that summarizes the proposed methodology. 


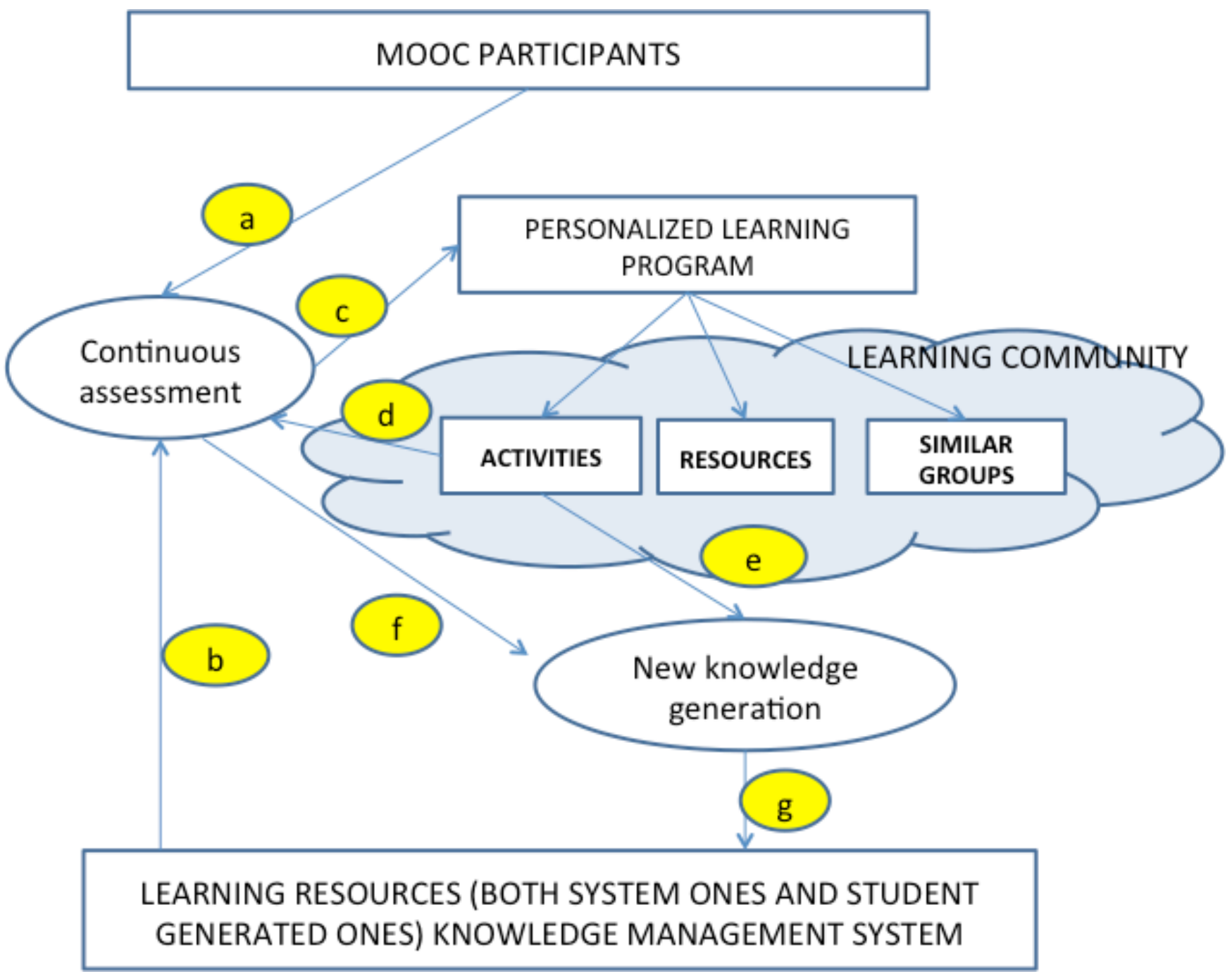

Figure 1. cMOOC adaptivity

\section{Initial adaptation}

- $\quad$ Profiles and profile learning goals are obtained from diagnostic assessment (Flow a - Fig. 1).

- $\quad$ The more suitable learning resources for each profile are selected throughout the knowledge management system (Flow $b-$ Fig. $1)$.

- The adaptive system builds up the personalized program for each profile. Participants of each profile compose the learning community (Flow c - Fig. 1).

\section{Continuous adaptation}

- $\quad$ Formative assessment is done taking into account the interactions and activities results (Flow d - Fig. 1).

- If it were necessary, the formative plan will be modified (again flows b and d of Fig. 1).

- The learning community, throughout the collaborative activities, generates new knowledge (Flow e - Fig. 1).

- The new generated knowledge is evaluated within the continuous assessment (also flow d is developed). New information for validation is generated if it were necessary the new knowledge must be managed (Flow $\mathrm{f}-$ Fig. 1).

- The system integrates the new knowledge to be managed within the course. Due to there exist new knowledge resources, the adaptation process may be refined. The new knowledge is social knowledge generated by the learning community (Flow $\mathrm{g}-$ Fig. 1). 
- There is a continuous spiral among a b, c, d, e, f and g flows. Every time that a spiral iteration occurs there is a major precision in the resources, in the collaborative activities and in the participants' affinity. This allows establishing closer and more effective conectivist links and, on the other hand, having a wide variety of knowledge resources.

\section{Once the MOOC edition is over}

- Two products have been generated: the learning community and knowledge management system.

- The knowledge management system is an adaptive system, therefore it allows finding useful knowledge for the learning community. This means the community will grow with new members.

- The learning community will generate new knowledge resources that will be managed by the knowledge management system.

- The new resources and the learning community will be able to be used by the next MOOC edition.

\section{CONCLUSIONS}

With the aim of completing the aMOOC notion mentioned above, this research proposal goes forward introducing the adaptivity also in the social component of the cMOOC. We look for this way having an impact on the completion rates, auto-learning improvement throughout interaction among peers and in the creation of learning communities that survive after a concrete MOOC edition ending. To do that, the research team is based on our previous experiences in educational adaptive systems and we propose the creation of a knowledge and learning community about Educational Innovation linked to this proposed MOOC/research-line.

\section{ACKNOWLEDGMENTS}

We would like to thank the Ministry of Industry, Commerce and Tourism of the Spanish Government for funding the project under identification number TSI-010103-2010-244, the Ministry of Science and Innovation of the Spanish Government for funding the project under identification number TIN2010-21695-C02-01, and the Regional Council of Education of Junta de Castilla y León (Spain) through the projects GR47 and MPLE (ref. SA294A12-2). Also, we thank the Government of Aragon and the European Social Fund for their support.

Finally, authors would like to thank the partners of theirs respective research groups for the received support (LITI, http://www.liti.es; GRIAL, http://grial.usal.es; and GIDTIC, http://gidtic.com).

\section{REFERENCES}

[1] ARANZADI, P., 2013. MOOCs (Cursos Online Masivos en Abierto).

[2] BARBOSA LEÓN, H., GARCÍA-PEÑALVO, F.J., RODRÍGUEZ CONDE, M.J., MORALES, E.M., and ORDÓÑEZ DE PABLOS, P., 2012. Adaptive Assessments using Open Specifications. International Journal of Distance Education Technologies (IJDET) 10, 4, 56-71. DOI= http://dx.doi.org/10.4018/jdet.2012100105.

[3] BERLANGA, A.J., GARCÍA, F.J., and CARABIAS, J., 2006. Authoring adaptive learning designs using IMS LD. In Adaptive Hypermedia and Adaptive Web-Based Systems, Proceedings, V. WADE, H. ASHMAN and B. SMYTH Eds. Springer Verlag, Berlin, 31-40. DOI= http://dx.doi.org/http://dx.doi.org/10.1007/11768012 5.

[4] BERLANGA, A.J. and GARCÍA-PEÑALVO, F.J., 2008. Learning Design in Adaptive Educational Hypermedia Systems. Journal of Universal Computer Science 14, 22, 3627-3647.

[5] DANIEL, J., 2012. Making Sense of MOOCs: Musings in a Maze of Myth, Paradox and Possibility. Journal of Interactive Media in Education 2012, 3.

[6] DEVLIN, K., 2013. MOOC Mania Meets the Sober Reality of Education. In The Huffington Post Blog.

[7] DOWNES, S., 2008. Places to go: Connectivism and connective knowledge. Innovate: Journal of Online Education 5, 1.

[8] FIDALGO BLANCO, Á., SEIN-ECHALUCE, M.L., CASTAÑEDA TOLEDO, O.A., and BORRÁS GENÉ, O., 2013. Software libre y conocimiento en abierto. https://http://www.miriadax.net/web/soft libre y conocimiento.

[9] FIDALGO BLANCO, Á., SEIN-ECHALUCE, M.L., LERÍS, D., and CASTAÑEDA, O., 2013. Teaching Innova Project: The incorporation of adaptable outcomes in order to grade training adaptability. Journal of Universal Computer Science In Press.

[10] GARCÍA-PEÑAlVO, F.J., CONDE, M.Á., ZANGRANDO, V., GARCÍA-HOLGADO, A., SEOANE, A.M., ALIER, M., GALANIS, N., BROUNS, F., VOGTEN, H., GRIFFITHS, D., MYKOWSKA, A., RIBEIRO-ALVES, G., and MINOVIĆ, M., 2013. TRAILER Project (Tagging, Recognition, Acknowledgment of Informal Learning Experiences). A Methodology to Make Learners' Informal Learning Activities Visible to the Institutions. Journal of Universal Computer Science, 19, 11, $1661-1683$.

[11] GARCÍA-PEÑALVO, F.J., GARCÍA DE FIGUEROLA, C., and MERLO, J.A., 2010. Open knowledge: Challenges and facts. Online Information Review 34, 4, 520-539. DOI= http://dx.doi.org/10.1108/14684521011072963.

[12] GARCÍA-PEÑALVO, F.J. and GARCÍA-CARRASCO, J., 2005. Educational hypermedia resources facilitator. Computers \& Education 44, 3 (Apr), 301-325. DOI= http://dx.doi.org/10.1016/j.compedu.2004.02.004.

[13] HILL, P., 2012. Four Barriers That MOOCs Must Overcome To Build a Sustainable Model. In e-Literature.

[14] JORDAN, K., 2013. MOOC Completion Rates: The Data.

[15] KAY, J., REIMANN, P., DIEBOLD, E., and KUMMERFELD, B., 2013. MOOCs: So Many Learners, So Much Potential ... . IEEE Intelligent Systems In Press.

[16] LERÍS, D. and SEIN-ECHALUCE, M.L., 2012. La personalización del aprendizaje: Un objetivo del paradigma educativo centrado en el aprendizaje. Arbor: Ciencia, pensamiento y cultura CLXXXVII, 3, 123-134.

[17] LEWIN, T., 2012. Instruction for Masses Knocks Down Campus Walls. In The New York Times, New York. 
[18] LIYANAGUNAWARDENA, T.R., ADAMS, A.A., and WILLIAMS, S.A., 2013. MOOCs: A Systematic Study of the Published Literature 2008-2012. The International Review of Research in Open and Distance Learning 14, 3, 202-227.

[19] MORRISON, D., 2013. The Ultimate Student Guide to xMOOCs and cMOOCs. In MOOC News \& Reviews.

[20] PAPPANO, L., 2012. The Year of the MOOC. In The New York Times, New York.

[21] PRIETO FERRARO, M., LEIGHTON ÁLVAREZ, H., and GARCÍA-PEÑALVO, F.J., 2004. Adaptive Educational Hypermedia Proposal Based on Learning Styles and Quality Evaluation. In Adaptive Hypermedia and Adaptive Web-Based Systems. 3rd International Conference, AH 2004, Proceedings P. DE BRA and W. NEJDL Eds. Springer Verlag, Berlin, 316-319.

[22] RAPP, S., 2012. MOOCS \& Adaptive Learning: Spanish MOOC.

[23] SCOPEO, 2013. SCOPEO INFORME No2: MOOC: Estado de la situación actual, posibilidades, retos y futuro. Universidad de Salamanca.

[24] SIEMENS, G., 2005. Connectivism: A learning theory for the digital age. International Journal of Instructional Technology and Distance Learning 2, 1, 3-10.

[25] SIEMENS, G., IRVINE, V., and CODE, J., 2013. Guest Editors' Preface to the Special Issue on MOOCs. An Academic Perspective on an Emerging Technological and Social Trend. MERLOT Journal of Online Learning and Teaching 9, 2, iii-vi.

[26] SONWALKAR, N., 2013. The First Adaptive MOOC: A Case Study on Pedagogy Framework and Scalable Cloud Architecture-Part I. MOOCs Forum 1, P, 22-29. DOI= http://dx.doi.org/10.1089/mooc.2013.0007.

[27] SONWALKAR, N., 2013. MOOC: A New Frontier in Open Education. In Proceedings of the United States Distance Learning Association 2013 National Conference (St. Louis, Missouri, USA2013).

[28] SONWALKAR, N., WILSON, J., NG, A., and SLOEP, P.B., 2013. State-of-the-Field Discussion. MOOCs Forum 1, P, 6-9. DOI $=$ http://dx.doi.org/10.1089/mooc. 2013.0006 .

[29] STEWART, B., 2013. Massiveness + Openness $=$ New Literacies of Participation? MERLOT Journal of Online Learning and Teaching 9, 2, 228-238.

[30] ZAPATA-ROS, M., 2013. MOOCs, una visión crítica y una alternativa complementaria: La individualización del aprendizaje y de la ayuda pedagógica. Campus Virtuales. Revista Científica Iberoamericana de Tecnología Educativa II, 1, 20-38. 